\title{
Respiratory Management in Patients with Severe Brain Injury
}

Karim Asehnoune ${ }^{1,2^{*}}$, Antoine Roquilly ${ }^{1,2}$ and Raphaël Cinotti ${ }^{1}$

\begin{abstract}
This article is one of ten reviews selected from the Annual Update in Intensive Care and Emergency Medicine 2018. Other selected articles can be found online at https://www.biomedcentral.com/collections/ annualupdate2018. Further information about the Annual Update in Intensive Care and Emergency Medicine is available from http://www.springer.com/ series/8901.
\end{abstract}

\section{Background}

Severe brain injuries, such as traumatic brain injury (TBI), intracranial hemorrhage or stroke are a common cause of intensive care unit (ICU) admission and mechanical ventilation initiation [1]. Mechanical ventilation is frequently applied to protect the airway from the risk of aspiration and to prevent both hypoxemia and hypercapnia, which are two major systemic factors of secondary brain insult. Recent guidelines [2] recommend that prolonged prophylactic hyperventilation with $\mathrm{PCO}_{2} \leq 25 \mathrm{mmHg}$ should be avoided, but the ventilator settings, including those to set tidal volume or positive end-expiratory pressure (PEEP), remain undetailed. Observational data suggest that brain injury patients are delivered higher tidal volume and lower PEEP levels than non-neurological patients [3] but they have longer mechanical ventilation duration, and higher rates of hospital-acquired pneumonia $[4,5]$, tracheostomy and mortality than non-neurologic patients [3]. The respiratory management is further complex because weaning these patients from mechanical ventilation and the decision to extubate remain two challenging issues [6]. Indeed, guidelines for the weaning of mechanical ventilation in ICU patients were developed 10 years ago [7], but owing to the lack of

\footnotetext{
* Correspondence: karim.asehnoune@chu-nantes.fr

${ }^{1}$ University Hospital of Nantes, Intensive Care Unit, Anesthesia and Critical Care Department, Hôtel Dieu, Nantes, France

2University Hospital of Nantes, Laboratoire UPRES EA 3826 "Thérapeutiques cliniques et expérimentales des infections", Nantes, France
}

robust evidence in the literature, no clear recommendations are currently available in the neuro-ICU setting.

Interest in the respiratory management of brain injury patients has increased recently. In particular, the use of protective ventilation in the early phase of brain injury $[8,9]$ has been evaluated, and new data regarding the criteria compatible with successful extubation [10-12] have been gathered.

In this chapter, we will focus on the most recent data available in the neuro-ICU field regarding respiratory management, from the early phase of mechanical ventilation initiation to liberation from mechanical ventilation and extubation.

\section{Historical Practices in Mechanical Ventilation Tidal Volume}

After brain injury, impaired consciousness and brain-stem reflexes induce hypoventilation and lead to aspiration. The first aim of mechanical ventilation is to protect the airway through tracheal intubation. Current guidelines recommend that endotracheal intubation should be performed systematically when the Glasgow Coma Score (GCS) is $\leq 8$ [2]. In the first days after brain injury, hypoxemia and hyper/hypocapnia lead to secondary brain insults, which alter the outcome [13]. Treatment of hypoxemia consists of increasing the inspired oxygen fraction $\left(\mathrm{FiO}_{2}\right)$ delivery with a target of $\mathrm{PaO}_{2}>60 \mathrm{mmHg}$ [2], which can be modified if brain ischemia is diagnosed by multimodal monitoring (low tissue oxygen tension $\left[\mathrm{PtiO}_{2}\right]$ and low jugular venous oxygen saturation $\left[\mathrm{SvjO}_{2}\right]$ ) [14]. $\mathrm{PaCO}_{2}$ is a powerful determinant of cerebral blood flow (CBF), which impacts intracranial pressure (ICP) [2]. An adequate control of $\mathrm{PaCO}_{2}$ within a $32-45 \mathrm{mmHg}$ range, even at the very early phase, was associated with a better outcome [15]. The maintenance of normal levels of $\mathrm{PaCO}_{2}$ is thus recommended throughout the TBI course [2]. Nonetheless, no consensus is available to set the respiratory rate and the tidal volume in order to reach the $\mathrm{PaCO}_{2}$ target, and in daily practice, practitioners usually increase tidal volume, in order to provide better $\mathrm{PaCO}_{2}$ control (Table 1). 
Table 1 Evolution of respiratory care bundle in patients with brain injury [8-12]

\begin{tabular}{lll}
\hline & Current practice & Evolution of practice \\
\hline Tidal volume & $>8 \mathrm{ml} / \mathrm{kg} \mathrm{IBW}$ & $6-7 \mathrm{ml} / \mathrm{kg} \mathrm{IBW}$ \\
PEEP & $0-3 \mathrm{cmH}_{2} \mathrm{O}$ & $\geq 5 \mathrm{cmH}_{2} \mathrm{O}$ \\
Extubation & Awaiting recovery & Negative fluid balance \\
management & or awareness & Cough \\
& & Gag reflex \\
& & VISAGE score: \\
& & - Age $<40$ \\
& & - GGS $>10$ \\
& & - Visual pursuit \\
Tracheostomy management & $?$ \\
\hline
\end{tabular}

PEEP positive end-expiratory pressure, GCS Glasgow Coma Score, IBW ideal body weight

In a multicenter nationwide observational study, patients with brain injury had a comparable mean tidal volume compared to non-neurologic patients, with a median of $9 \mathrm{ml} / \mathrm{kg}$ of ideal predicted body weight [3]. However, a significantly lower proportion of patients with intracranial hemorrhage (15\%) received protective ventilation on day 1 of mechanical ventilation, probably because of the fear of hypercapnia [3]. Because lung injuries were observed in animal models of brain injury and associated with the release of danger-associated molecular patterns (DAMPs) and with lung injury [16], it is reasonable to propose that brain injury is a risk factor for ventilator-induced lung injury (VILI) and that low tidal volume could be of interest in these patients. Indeed, it is now well established that high tidal volume ventilation leads to VILI [17] and, in neurologic ICU studies, the use of high tidal volume is associated with an increased rate of acute respiratory distress syndrome (ARDS), worsening outcomes [18].

\section{Low Positive End-expiratory Pressure}

PEEP increases the intrathoracic pressure and consequently may impair the central venous return leading to increased ICP. In a study performed in nine patients with brain injury [19], the authors showed a positive correlation between PEEP and ICP during recruitment maneuvers. However, in an experimental study in healthy pigs, PEEP increase did not affect ICP [20]. In patients with subarachnoid hemorrhage [20], PEEP impaired CBF by a decrease in mean arterial pressure (MAP) although ICP was not altered. It has therefore been advocated to use low or null PEEP in mechanically ventilated patients with brain injury, and $80 \%$ of patients with brain injury receiving mechanical ventilation, are delivered a PEEP $\leq 5 \mathrm{cmH}_{2} \mathrm{O}$ [3].

\section{Weaning from Invasive Mechanical Ventilation and Extubation}

The population of severe brain injury patients is at high risk of extubation failure with rates up to $38 \%$ [21].
Currently, no strategy has been described regarding weaning or extubation and brain injury patients were hardly described in the latest guidelines [7]. The clinical features and level of arousal compatible with successful extubation are still debated in brain injury patients and, therefore, the rates of extubation failure and delayed extubation remain high in this population. Extubation failure is associated with significant morbidity: nosocomial pneumonia, longer mechanical ventilation duration, increased ICU length of stay and higher mortality $[6,10,11]$, but the cause of extubation failure is probably more deleterious than the failure itself [6]. The fear of extubation failure explains the high rate of delayed extubation in neuro-ICU patients (extubation is considered as delayed when patients are not extubated within $48 \mathrm{~h}$ of meeting defined readiness criteria [6]), even though delaying extubation is not a guarantee of success [6]. Delaying extubation leads to an increased rate of pneumonia altering the neurological outcome; the high rate of delayed extubation also increases healthcare costs [6].

\section{New Perspectives: How to Set Mechanical Ventilation in Clinical Practice}

There was a recent reappraisal about the effects of PEEP on cerebral perfusion pressure (CPP). In a retrospective study in 341 patients [22], the authors noted a statistically significant decrease in CPP with increase in PEEP, but CPP remained within the therapeutic target. Moreover, no data were provided about the patients' volemic status; this is important because PEEP may alter CPP in hypovolemic conditions. In a pilot prospective study performed in 20 patients with TBI and ARDS [23], the authors increased PEEP up to $15 \mathrm{cmH}_{2} \mathrm{O}$. There was no significant change in ICP or CPP and, importantly, the authors reported a significant improvement in brain tissue oxygenation with higher levels of PEEP. In conclusion, it seems that an increase in PEEP can be safely applied in ARDS patients with brain injury, provided that they are normovolemic, and may even have beneficial cerebral effects. Our group recently confirmed the safety of PEEP by showing that PEEP $>5 \mathrm{cmH}_{2} \mathrm{O}$ did not alter the ICP in patients with severe brain injury [9].

The use of low tidal volume within a protective ventilation strategy in the general ICU population with ARDS [24] or in the perioperative setting [25], is strongly associated with improved outcomes. Our group recently evaluated, in two before-after studies, the efficacy of a protective ventilation strategy in patients with brain injury:

1) A study [8] in two ICUs including 499 patients evaluated a bundle of care with a protective ventilation strategy (tidal volume between 6 and $8 \mathrm{ml} / \mathrm{kg}$ of ideal predicted bodyweight and PEEP $>3$ $\mathrm{cmH}_{2} \mathrm{O}$ ) and early extubation (when GCS $\geq 10$ and cough was obtained). An improvement in the 
number of ventilatory-free days was observed during the intervention period.

2) A multicenter nationwide before-after study in 749 brain injury patients was conducted to evaluate the effects of protective ventilation $(\leq 7 \mathrm{ml} / \mathrm{kg}$ of ideal predicted body weight and a PEEP between 6 and 8 $\mathrm{cmH}_{2} \mathrm{O}$ ) associated with early extubation [9]. There was no difference in the number of ventilatory-free days at day 90 between the two periods. However, in the subgroup of patients in which all the recommendations were applied (protective ventilation and early extubation), there was a significant improvement in the number of ventilator free days at day 90 and in the mortality rate.

In both these studies [8, 9], the use of protective ventilation did not alter outcomes or impair ICP provided that the level of $\mathrm{PaCO}_{2}$ was monitored and maintained within normal ranges. These results also provide important, simple and applicable data to attending physician on how to reach the goals of $\mathrm{PaCO}_{2}$ suggested by international guidelines [2] with a strategy of modifying respiratory rate rather than tidal volume.

\section{When Should we Perform Extubation After Brain Injury?}

The level of arousal is a major issue in deciding when to safely perform extubation, but multiple pitfalls persist in its bedside evaluation. Coplin et al. pointed out that delaying extubation, in order to wait for sufficient neurological recovery, did not guarantee successful extubation and was associated with increased nosocomial pneumonia, ICU and hospital lengths of stay and costs [6]. Navalesi et al. proposed algorithm-based extubation when patients displayed a GCS $\geq 8$ with audible cough during suctioning, and showed a significant improvement in extubation success [26]. Namen et al. showed that a GCS of $8 \mathrm{had}$ the highest area under the receiver operating curve for predicting successful extubation [21].

Surprisingly, in a multicenter study including 192 patients, and in a monocenter cohort of 140 patients [11], higher GCS was not associated with extubation success [12]. A major limitation potentially explaining the discrepancies between these studies is that the GCS has never been validated in intubated patients, and it should be remembered that quantification of the verbal component is impossible in intubated patients, especially after brain injury. Some authors have arbitrarily decided to score the verbal component as 1 in all intubated patients [6], whereas others chose to score the verbal component as 1 in non-communicating patients and as 4 in patients who tried to speak with the endotracheal tube [10]. In other studies [21, 26], the evaluation of the verbal component is not available. This observation may explain why the GCS has been inconsistently reported as a factor associated with extubation success, and other tools of arousal evaluation are mandatory.

Further specific neurologic features compatible with safe extubation have been identified. In a multicenter study performed in 437 patients, our group aimed to develop a standardized specific physical examination on the day of extubation that could predict extubation success [10]. Age $<40$ years old, visual pursuit, attempts to swallow and a GCS $>10$ on the day of extubation were independent markers of successful extubation. Based on these four items, the predictive VISAGE score was built, which predicted at least $90 \%$ of episodes of extubation success when three items were present. In another monocenter study in 140 patients [11], visual pursuit and preserved upper airway reflexes were predictive factors of extubation success. In 192 patients [12], in another monocenter study, younger age, negative fluid balance and the presence of cough were predictive factors. Cough was also identified as predictive in a monocenter study in 311 patients with TBI [27]. We summarize the clinical features that may predict successful extubation after brain injury in Table 1 . Large multicenter studies need to be performed to better delineate the impact of predictive factors of extubation success in order to enhance the benefit/risk balance in the decision to extubate and improve outcomes of brain injury patients (Table 2).

\section{When Should we Perform Tracheostomy After Brain Injury?}

Owing to the complicated extubation process in patients with brain injury, tracheostomy appears an interesting approach. Debate remains over the benefit of early versus late tracheostomy [28] because early tracheostomy may be associated with an increase in the number of ventilator-free days. Data on the subject are scarce in the neuro-ICU literature (Table 3). Two recent studies have used large databases to assess the potential effects of early versus late tracheostomy. In the first monocenter retrospective study performed in a trauma population [29], a propensity analysis matched for head and chest injury favored early tracheostomy with less pneumonia, lower mechanical ventilation duration and ICU length of stay. The second retrospective multicenter study in 1811 TBI patients [30] also supported an early tracheostomy policy. The mortality rate was similar between patients with early and late tracheostomy in both studies. The main issue is that these analyses are extracted from databases in which the reason why tracheostomy was performed is unknown. These results were challenged in a randomized parallel-group, controlled, open study in stroke patients [31] in which early tracheostomy did not result in a reduction in the ICU length of stay, which was the primary outcome, but resulted in lower mortality. This result should be cautiously interpreted because 
Table 2 Description of extubation failure rates and in-intensive care unit (ICU) mortality in brain-injured patients

\begin{tabular}{|c|c|c|c|c|c|}
\hline First author [ref] & $\begin{array}{l}\text { Number of patients } \\
\text { with brain injury }\end{array}$ & Baseline GCS & GCS at extubation & $\begin{array}{l}\text { Extubation failure } \\
\text { rate }(\%)\end{array}$ & $\begin{array}{l}\text { In-ICU mortality } \\
\text { rate }(\%)\end{array}$ \\
\hline $\begin{array}{l}\text { Navalesi [26] (intervention/ } \\
\text { control groups) }\end{array}$ & $165 / 153$ & $9.4 \pm 1.9 / 9.3 \pm 1.9$ & $10.6 \pm 0.7 / 10.5 \pm 0.9$ & $5 / 12$ & $1 / 4$ \\
\hline Qureshi [32] & 69 & Unknown & Unknown & 67 & 39 \\
\hline Reis [35] (success/failure groups) & 311 & $9.7 \pm 4.4$ & Unknown & 13.8 & $3 / 14$ \\
\hline Coplin [6] & 136 & Unknown & Unknown & 17.4 & 16.1 \\
\hline $\begin{array}{l}\text { Namen [21] (intervention/ } \\
\text { control groups) }\end{array}$ & 100 & Unknown & $8.3 \pm 2.6$ & 38 & $41 / 31$ \\
\hline Karanjia [36] & 1265 & Unknown & $11 \pm 3$ & 6.1 & Unknown \\
\hline $\begin{array}{l}\text { Wendell [37] (success/failure } \\
\text { groups) }\end{array}$ & 37 & $11(8-14) / 11.5(7-14)$ & $13(9-14) / 10.5(8-14)$ & 21 & $8 / 20$ \\
\hline Godet [11] (success/failure groups) & 140 & $8(5-11) / 6(4-9)$ & $9(8-10) / 9(7-10)$ & 31 & $1 / 19$ \\
\hline $\begin{array}{l}\text { McCredie [12] (success/failure } \\
\text { groups) }\end{array}$ & 192 & $7(4-9) / 7(6-9)$ & $9(8-10) / 9(8-10)$ & 21 & $1 / 13$ \\
\hline $\begin{array}{l}\text { Asehnoune [10] (success/failure } \\
\text { groups) }\end{array}$ & 437 & $7(5-10) / 7(3-10)$ & $11(10-14) / 11(9-13)$ & 22.6 & $1.2 / 11.1$ \\
\hline
\end{tabular}

GCS Glasgow Coma Scale expressed as mean ( \pm standard deviation) or median (interquartile) accordingly. In-ICU mortality is displayed for the entire cohort or according to the extubation success/failure group and the intervention/control group whenever appropriate

only 60 patients were included and mortality was a secondary outcome.

In clinical practice, early tracheostomy is not recommended but could be considered in situations with high risk of extubation failure like infra-tentorial lesions [32], protracted mechanical ventilation or in patients with poor neurological recovery and/or after extubation failure.

\section{Extubation, Tracheostomy and Withdrawal of Life- sustaining Therapies After Brain Injury}

A major clinical issue regarding extubation and tracheostomy in the neuro-ICU setting, is that physicians fear that tracheostomy may facilitate weaning the patient from mechanical ventilation but sometimes with unacceptable neurologic damage. Extubation may be the last step of withdrawal of life-sustaining therapies. This practical aspect of end-of-life care has not been adequately addressed in neuro-ICU patients. A descriptive monocenter study confirmed that mechanical ventilation discontinuation accounted for $50 \%$ of deaths in a population of neurovascular patients (stroke, intracerebral hemorrhage or subarachnoid hemorrhage) [33]. In most studies regarding extubation in brain injury patients, patients undergoing withdrawal of life-sustaining therapies are not included [10,11], but the timing, modalities and consequences of extubation in this context are not addressed in the neuro-ICU literature.

Withdrawal of life-sustaining therapies is a complex process and its modalities after brain injury cannot be reduced only to extubation, which could remain successful even in comatose patients [6, 10-12].

\section{Conclusion}

Revisiting current strategies for respiratory management in patients with acute brain injury is important because no clear recommendations are currently available and

Table 3 Description of tracheostomy and mortality rates in patients with severe brain injury

\begin{tabular}{lllll}
\hline First author [ref] & $\begin{array}{l}\text { Number of } \\
\text { patients }\end{array}$ & $\begin{array}{l}\text { Tracheostomy, } \\
\mathrm{n}(\%)\end{array}$ & $\begin{array}{l}\text { General in-ICU } \\
\text { mortality, } \mathrm{n}(\%)\end{array}$ & $\begin{array}{l}\text { In-ICU mortality in patients } \\
\text { with tracheostomy, } \mathrm{n}(\%)\end{array}$ \\
\hline Navalesi [26] & 318 & $16(5)$ & $8(2)$ & Unknown \\
Qureshi [32] & 69 & $23(33)$ & $27(39)$ & Unknown \\
Reis [35] & 311 & $29(9)$ & $21(6)$ & Unknown \\
Coplin [6] & 136 & $4(3)$ & $22(16.1)$ & Unknown \\
Namen [21] & 100 & $29(29)$ & $36(36)$ & Unknown \\
Karanjia [36] & 1265 & $181(14)$ & Unknown & Unknown \\
Wendell [37] & 37 & $3(8)$ & $5(13.5)$ & Unknown \\
Godet [11] & 140 & $9(6.4)$ & $9(6.4)$ & Unknown \\
Asehnoune [10] & 437 & $40(9.1)$ & $15(3.4)$ & $2(0.4)$
\end{tabular}


respiratory management in general may impact neurological outcomes. It is now clear that PEEP has minor effects on CPP in euvolemic patients and could even have positive consequences on brain tissue oxygenation. Protective ventilation, with low tidal volumes $(6-8 \mathrm{ml} / \mathrm{kg}$ of ideal body weight), can be safely performed after brain injury, but its positive effects on outcome have to be better delineated. Extubation remains challenging in the neuro-ICU setting. Waiting for a patient's full neurological recovery is not mandatory and some specific features, such as visual pursuit, cough, and deglutition, may help the attending physician to perform extubation. Tracheostomy can be considered, but the best timing and the selection of patients who might benefit from this strategy remain unknown. Finally, the development of quality improvement projects is a crucial step in improving outcomes of patients with acute brain injury [34].

\section{Acknowledgements}

Not applicable.

\section{Funding}

Publications costs were funded by the University hospital of Nantes.

\section{Availability of data and materials}

Not applicable.

\section{Author's contributions}

All authors have analysed data, written the article and edited the manuscript. All authors have read and approved the final manuscript.

\section{Ethics approval and consent to participate}

All studies cited in the review were approved by ethics committee. Patients or next-of-kin, whenever appropriate, gave their consent in the participation in these studies.

\section{Consent for publication}

Not applicable.

\section{Competing interests}

Karim Asehnoune received grants from $\mathrm{LFB}^{\oplus}$, Fresenius ${ }^{\oplus}$ and Baxter ${ }^{\oplus}$.

\section{Publisher's Note}

Springer Nature remains neutral with regard to jurisdictional claims in published maps and institutional affiliations.

\section{Published online: 20 March 2018}

\section{References}

1. Esteban A, Anzueto A, Frutos F, et al. Characteristics and outcomes in adult patients receiving mechanical ventilation: a 28-day international study. JAMA. 2002;287:345-55.

2. Carney N, Totten AM, O'Reilly C, et al. Guidelines for the management of severe traumatic brain injury, fourth edition. Neurosurgery. 2017;80:6-15.

3. Pelosi P, Ferguson ND, Frutos-Vivar F, et al. Management and outcome of mechanically ventilated neurologic patients. Crit Care Med. 2011;39:1482-92.

4. Lepelletier $D$, Roquilly $A$, Demeure dit latte $D$, et al. Retrospective analysis of the risk factors and pathogens associated with early-onset ventilatorassociated pneumonia in surgical-ICU head-trauma patients. J Neurosurg Anesthesiol. 2010;22:32-7.

5. Cinotti R, Dordonnat-Moynard A, Feuillet F, et al. Risk factors and pathogens involved in early ventilator-acquired pneumonia in patients with severe subarachnoid hemorrhage. Eur J Clin Microbiol Infect Dis. 2014;33:823-30.
6. Coplin WM, Pierson DJ, Cooley KD, et al. Implications of extubation delay in brain-injured patients meeting standard weaning criteria. Am J Respir Crit Care Med. 2000;161:1530-6.

7. Boles J-M, Bion J, Connors A, et al. Weaning from mechanical ventilation. Eur Respir J. 2007;29:1033-56.

8. Roquilly $A$, Cinotti $R$, Jaber $\mathrm{S}$, et al. Implementation of an evidence-based extubation readiness bundle in 499 brain-injured patients. a before-after evaluation of a quality improvement project. Am J Respir Crit Care Med. 2013;188:958-66.

9. The BI-VILI study group, Asehnoune K, Mrozek S, et al. A multi-faceted strategy to reduce ventilation-associated mortality in brain-injured patients. The BI-VILI project: a nationwide quality improvement project. Intensive Care Med. 2017;287:345-14.

10. Asehnoune K, Seguin P, Lasocki S, et al. Extubation success prediction in a multicentric cohort of patients with severe brain injury. Anesthesiology. 2017;127:338-46.

11. Godet T, Chabanne R, Marin J, et al. Extubation failure in brain-injured patients: risk factors and development of a prediction score in a preliminary prospective cohort study. Anesthesiology. 2017;126:104-14.

12. McCredie VA, Ferguson ND, Pinto RL, et al. Airway management strategies for brain-injured patients meeting standard criteria to consider extubation. a prospective cohort study. Ann Am Thorac Soc. 2017;14:85-93.

13. Rosenfeld JV, Maas Al, Bragge P, et al. Early management of severe traumatic brain injury. Lancet. 2012;380:1088-98.

14. Longhi L, Pagan F, Valeriani V, et al. Monitoring brain tissue oxygen tension in brain-injured patients reveals hypoxic episodes in normal-appearing and in peri-focal tissue. Intensive Care Med. 2007;33:2136-42.

15. Davis DP, Idris AH, Sise MJ, et al. Early ventilation and outcome in patients with moderate to severe traumatic brain injury. Crit Care Med. 2006;34:1202-8.

16. López-Aguilar J, Villagrá A, Bernabé F, et al. Massive brain injury enhances lung damage in an isolated lung model of ventilator-induced lung injury. Crit Care Med. 2005;33:1077-83.

17. Gattinoni L, Protti A, Caironi P, Carlesso E. Ventilator-induced lung injury: The anatomical and physiological framework. Crit Care Med. 2010;38:S539-48.

18. Mascia L, Zavala E, Bosma K, et al. High tidal volume is associated with the development of acute lung injury after severe brain injury: an international observational study. Crit Care Med. 2007:35:1815-20.

19. Zhang XY, Yang ZJ, Wang QX, Fan HR. Impact of positive end-expiratory pressure on cerebral injury patients with hypoxemia. Am J Emerg Med. 2011;29:699-703.

20. Muench E, Bauhuf $\mathrm{C}$, Roth $\mathrm{H}$, et al. Effects of positive end-expiratory pressure on regional cerebral blood flow, intracranial pressure, and brain tissue oxygenation. Crit Care Med. 2005;33:2367-72.

21. Namen AM, Ely EW, Tatter SB, et al. Predictors of successful extubation in neurosurgical patients. Am J Respir Crit Care Med. 2001;163:658-64.

22. Boone MD, Jinadasa SP, Mueller A, et al. The effect of positive endexpiratory pressure on intracranial pressure and cerebral hemodynamics. Neurocrit Care. 2016;26:174-81.

23. Nemer SN, Caldeira JB, Santos RG, et al. Effects of positive end-expiratory pressure on brain tissue oxygen pressure of severe traumatic brain injury patients with acute respiratory distress syndrome: a pilot study. J Crit Care. 2015;30:1263-6.

24. Bellani G, Laffey JG, Pham T, et al. Epidemiology, patterns of care, and mortality for patients with acute respiratory distress syndrome in intensive care units in 50 countries. JAMA. 2016;315:788.

25. Futier E, Constantin J-M, Paugam-Burtz C, et al. A trial of intraoperative lowtidal-volume ventilation in abdominal surgery. N Engl J Med. 2013:369:428-37.

26. Navalesi P, Frigerio P, Moretti MP, et al. Rate of reintubation in mechanically ventilated neurosurgical and neurologic patients: evaluation of a systematic approach to weaning and extubation. Crit Care Med. 2008;36:2986-92.

27. dos HFC R, Gomes-Neto M, Almeida MLO, et al. Development of a risk score to predict extubation failure in patients with traumatic brain injury. J Crit Care. 2017:42:218-22.

28. Young D, Harrison DA, Cuthbertson BH, et al. Effect of early vs late tracheostomy placement on survival in patients receiving mechanical ventilation: the TracMan randomized trial. JAMA. 2013;309:2121-9.

29. Hyde GA, Savage SA, Zarzaur BL, et al. Early tracheostomy in trauma patients saves time and money. Injury. 2015;46:110-4.

30. Alali AS, Scales DC, Fowler RA, et al. Tracheostomy timing in traumatic brain injury. J Trauma Acute Care Surg. 2014;76:70-8.

31. Bosel J, Schiller P, Hook Y, et al. Stroke-related early tracheostomy versus prolonged orotracheal intubation in neurocritical care trial (SETPOINT): a randomized pilot trial. Stroke. 2012;44:21-8. 
32. Qureshi Al, Suarez Jl, Parekh PD, Bhardwaj A. Prediction and timing of tracheostomy in patients with infratentorial lesions requiring mechanical ventilatory support. Crit Care Med. 2000;28:1383-7.

33. Holloway RG, Ladwig S, Robb J, et al. Palliative care consultations in hospitalized stroke patients. J Palliat Med. 2010;13:407-12.

34. Middleton S, McElduff P, Ward J, et al. Implementation of evidence-based treatment protocols to manage fever, hyperglycaemia, and swallowing dysfunction in acute stroke (QASC): a cluster randomised controlled trial. Lancet. 2011;378:1699-706.

35. Reis HF, Almeida MLO, Silva MFD, de Rocha MS. Extubation failure influences clinical and functional outcomes in patients with traumatic brain injury. J Bras Pneumol. 2013;39:330-8.

36. Karanija N, Nordquist D, Stevens R, Nyquist P. A clinical description of extubation failure in patients with primary brain injury. Neurocrit Care. 2011;15:4-12.

37. Wendell LC, Raser J, Kasner S, Park S. Predictors of extubation success in patients with middle cerebral artery acute ischemic stroke. Stroke Res Treat. 2011;2011:1-5 